\title{
Age(ism) in digital information provision: The case of online public services for older adults
}

\author{
Maria Sourbati \\ School of Art, Design and Media, College of Art and Humanities \\ University of Brighton \\ m. sourbati@brighton.ac.uk
}

\begin{abstract}
This paper draws on an empirical investigation of how older people are represented on the websites providing social care service information in the inner London Boroughs. My research questions follow the work of Loos [1] [2] on the relationship between representations of older age, information accessibility and access to digital services. Mirroring Loos and reflecting the specificities of the fieldwork my investigation found older people were largely invisible as a diverse group of citizens in the emerging cultures of digital public service. The images of older adults were few and lacked diversity. Inner London has an ethnically and culturally diverse population yet older adults were commonly represented though images of frail white women. The paper highlights representational politics of older age in digital public service information provision and their consequences for access and social inclusion; intra-generational diversity; ageism as a prevalent form of social discrimination.
\end{abstract}

Keywords: age, ageism, access, inclusion, digital public service, intragenerational diversity

\section{$1 \quad$ Introduction}

This paper draws on an empirical investigation of digital information provision in local government websites to discuss older age, diversity and inclusion in digital public service. Its broader context is the constant increase of ICT innovation, media use and ageing. As an ever increasing range of interpersonal, professional and civic communication activity is today digitally mediated, access to digital information services for a diverse population is essential to transact with government and market actors. In digital information services such as healthcare, mechanisms that control or facilitate our access to the media-technology interfaces (e.g., navigation systems, website design including the representation of their target users) have an impact on our access to services that support independent living, good life and life in the community etc. Media access and diversity are therefore gaining renewed currency. The 'digital turn' can be seen to increase the relevance of those legacy media policy values as well as the complexity and elusiveness that characterizes their implementation. The ageing turn, which is inscribed in the biological and social logic of ageing in our society [3, pp. 94, 102] further accentuates them. This paper is a contribution to the policy discussion of digital media access for a diverse population of older people $[1,2,4,5]$ in our ageing and ageist societies.

The more specific context of the paper relates UK government's 'digital by default' strategy to deliver public service information online/digital only. According to the 2013 Government Digital Strategy (Government Digital Strategy, December 2013 Update, Executive Summary https://www.gov.uk/government/publications/governmentdigital-strategy/ government-digital-strategy) the UK public sector is now moving from multiple channels to delivery of public service information that is online/digital ${ }^{1}$ only. Having committed to a target of digital by default public services by March 2015 (Government Digital Strategy, December 2013 Update, Executive Summary https://www.gov.uk/government/publications/government-digital-strategy/ government-digital-strategy) the strategy

1 Information services are defined by government as covering the publishing of information to help citizens and businesses in their engagement with government (https://www.gov.uk/government/publications/government-digital-strategy/governmentdigital-strategy\#introduction). 'Digital' is meant as a synonym to 'online'. The policy glossary reads: 'By 'digital', we mean internet-enabled; such as desktop, laptop, tablet, mobile or digital devices not yet invented' (Government Digital Strategy, 10/12/2013 https://www.gov.uk/government/publications/government-digital-strategy/government-digital-strategy\#annex-1glossary) 
aimed to increase delivery of their services online by increasing the level of use of digital public services. According to government 'Digital by Default' wishes to encourage everyone who can use digital services independently to do so. For those who cannot use digital ICTs for themselves digital information provision will be implemented by assisted digital use, whereby individuals can access a service with help by proxy users. Government has declared assisted access will be the only 'non-digital' way to access services 'for the people who really need it'. (Government Approach to assisted digital December 2012 http://publications.cabinetoffice.gov.uk/digital/assisted/ accessed November 2013). Social health care information services are a core area of public service provision. The ideology of the government strategy of digital social policy can be summarized as 'fair access to services for those who are entitled to them.' (http://publications.cabinetoffice.gov.uk/digital/assisted/). Defined that way, 'fair' access is subject to availability of media-technological infrastructure, including internet connectivity, and digital information provision to a diversity of users. It will be determined by policy responses to understanding of who the users are, who can and who cannot use digital services - perceptions of accessibility, diversity, and information provision to a potential diversity of users.

The remainder of this paper discusses conceptualizations of older age in research and trends in internet use and the social demographics of the older adult population in the UK, and reports the findings of a study of older adults' representations in Local Authority social care service webpages. The final section discusses the findings and concludes the paper.

\section{Media technologies and the perils of abstracted, temporally bound age}

Older people are a large and growing group. We commonly refer to older adults as a single generational group, membership of which is defined by a shared chronological location. Frequently used to mean 'cohort' the term [older] generation defines people in terms of a specific chronological age range [6, pp. 31,33]. Oddly, we take this common location to span five decades of birth dates, from 50+ to $100+$ years. We then conceptualize age on the basis of assumptions of homogenous context. This politics is reproduced in media and ICT research though practical reasons that often inhibit research on the 70+ year-olds using popular research tools (e.g. limitations of telephone surveys: people living in retirement or residential homes without individual phone line are hard to get hold of ) [7 p. 3]. When it comes to the use of new media technologies older people are treated as 'residual category' encompassing all ages above 50 or 60 years [7, p.13]. Popular labels of digital natives and immigrants [8] can be seen to play upon exactly this abstraction and related socio-technical and life-world dichotomies, which are beyond the scope of this conference paper to discuss.

Society, research and policy communities are waking up to age. More recent empirical investigations of older/younger people and new ICTs have exposed substantial limitations in dominant conceptualizations of mediatechnological and age boundaries and the assumed clear-cut temporal-and spatial divisions in media use [1, 2, 4, 5, $7,9,10]$. This new and growing body of research examines the contexts of the lived experience of age including the variability of media technology and internal diversity or intra-age variability [9]. Older people encompass an 'incredibly diverse' group of users of media technologies in terms of characteristics and functionality [11, p.152, life events and experiences of education, jobs held, relational/familial networks and all forms of cultural capital. Differences tend to increase with age as a result of increased variability in cumulative life experiences [12, p.68; 8 , p.265; 13, pp. 109-110] according to the concept of 'aged heterogeneity', originally used by Dannefer [14, pp.360362]. There is also a growing polarisation among people belonging in the same age group, particularly during the last part of the life course. Many older groups experience a restriction in social space and limited choice in access to adequate housing, leisure, health and communication infrastructure etc. [6, pp.129-130]. Significant inequalities within the older population including functions of education, such as sex/gender can determine their place and location in the new technology landscape [3, pp.101-102].

\section{Intra-generational variability: sex, ethnic origin and the internet}

The body of older internet users grows constantly. Official internet use statistics reflect this increase in the ageing of media users. A majority of older people in the UK are using the internet today. In 2013 fifty nine per cent (59\%) of people aged over 65 were online (https://www.gov.uk/government/publications/digital-landscape-research/digitallandscape-research.) According to the UK Office of National Statistics seven in ten of those aged 65 to 74 and four 
out of ten adults aged 75+ had used the internet in 2014 [15] http://www.ons.gov.uk/ons/rel/rdit2/internet-accessquarterly-update/q1-2014/stb-ia-q1-2014.html\#tab-Age Seventy-one per cent of adults aged 65-74 had used the internet in Q1 2014 and thirty-seven per cent of adults aged 75 years and over, the latter category representing 1.8 million people. Socio-demographic data for older users reveal areas of inequality which are commonly understood as a thing of the past in countries with high internet diffusion. Sex is a notable one. Like race and ethnicity, sex it is no longer considered by the 'digital divide' research as a factor of social different in internet usage in the UK [16]. According to national statistics there is little difference in internet use between men and women in all groups under 65 years of age [15]. However, sex appears to determine access to the internet among older groups. Men over the age of 75 are twice as likely to use the internet compared to women of the same age [17] In 2014 five in ten men aged 75+ had used the internet against three in every ten women in the same age group [15].

These differences can be understood as functions of inequality in education and wealth/social position, which have been a constant backdrop in adults' engagement with digital media. Of about $18 \%$ of the UK population who had never used the internet in 2013, blue collar non-users were more likely than other groups to identify age (78\%) as reasons not to use the Internet [18, p. 55]. By contrast 95 per cent of all adults with a higher educational qualification had used the internet in the UK [18, p. 19]. The relevance of education and social position and suggested correlations of age, sex and education in the UK mirror similar trends in international data [7].

Older adult cohorts are today becoming more ethnically diverse in the UK. According to the ONS [17]the 2011 census data show that between 2001 and 2011 the 65 and over age group became slightly more ethnically diverse. The older population identifying as White British increased in size from 7.8 million to 8.5 million but the proportion of the age group they accounted for decreased from $94 \%$ in 2001 to $92 \%$ in 2011 . This compares with much larger changes in the under 65 age group, which saw the proportion of the population who were White British decrease from 86\% in 2001 to $72 \%$ in 2011 (p. 9 in http://www.ons.gov. uk/ ons/ dcp171776_342117.pdf) Ethnic diversity is far greater in the city of London. Tables one and two present the ethnic breakdown (White/Black \& Other Minority Ethnic, BAME) of adult populations aged over 65 years and of the total population of city residents in the twelve inner London Boroughs, based on data made available by the Greater London Authority in 2013 (http://data.london. gov.uk/datastore/applications/ custom-age-range-creator-tool-gla-ethnic-group-population-projections-borough.

Table 1. Inner London population by ethnic origin (White/BAME) Data source GLA 2013

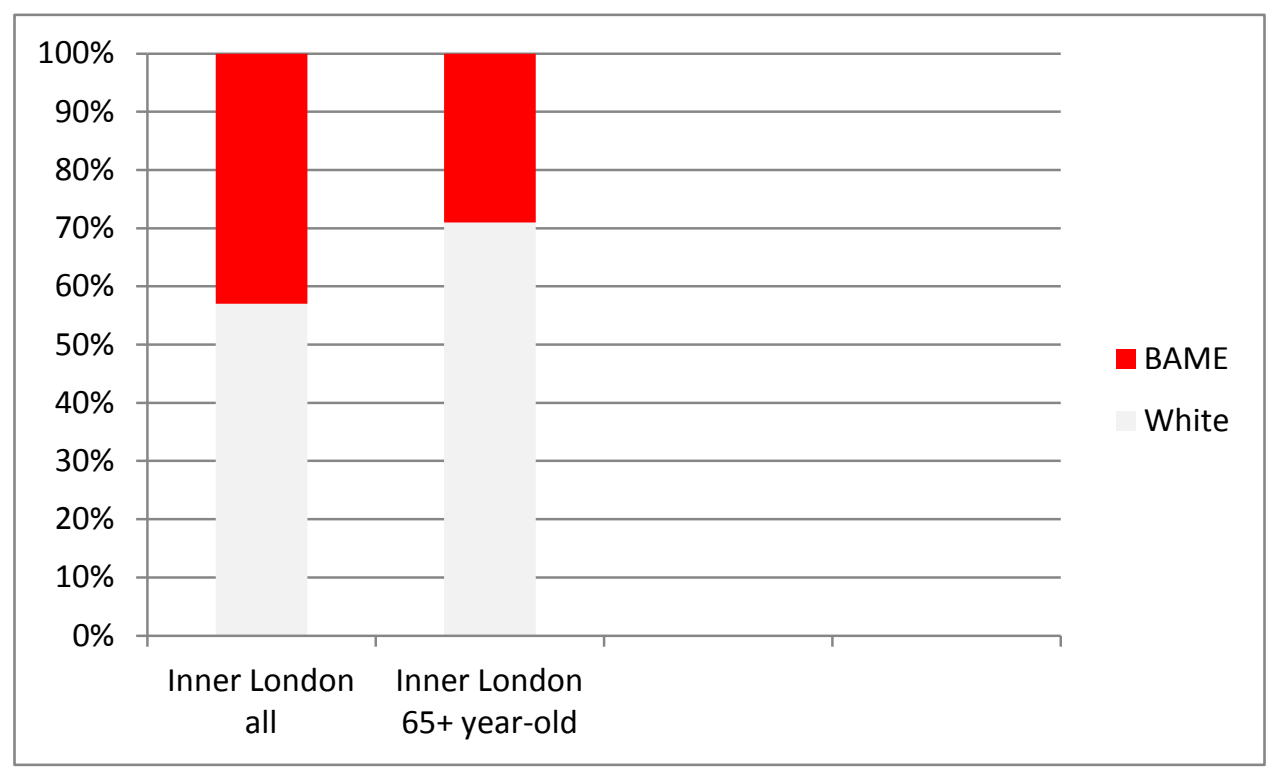


Table 2. Ethnic origin (white / BAME) 65+ year olds by Borough. Data source GLA 2013

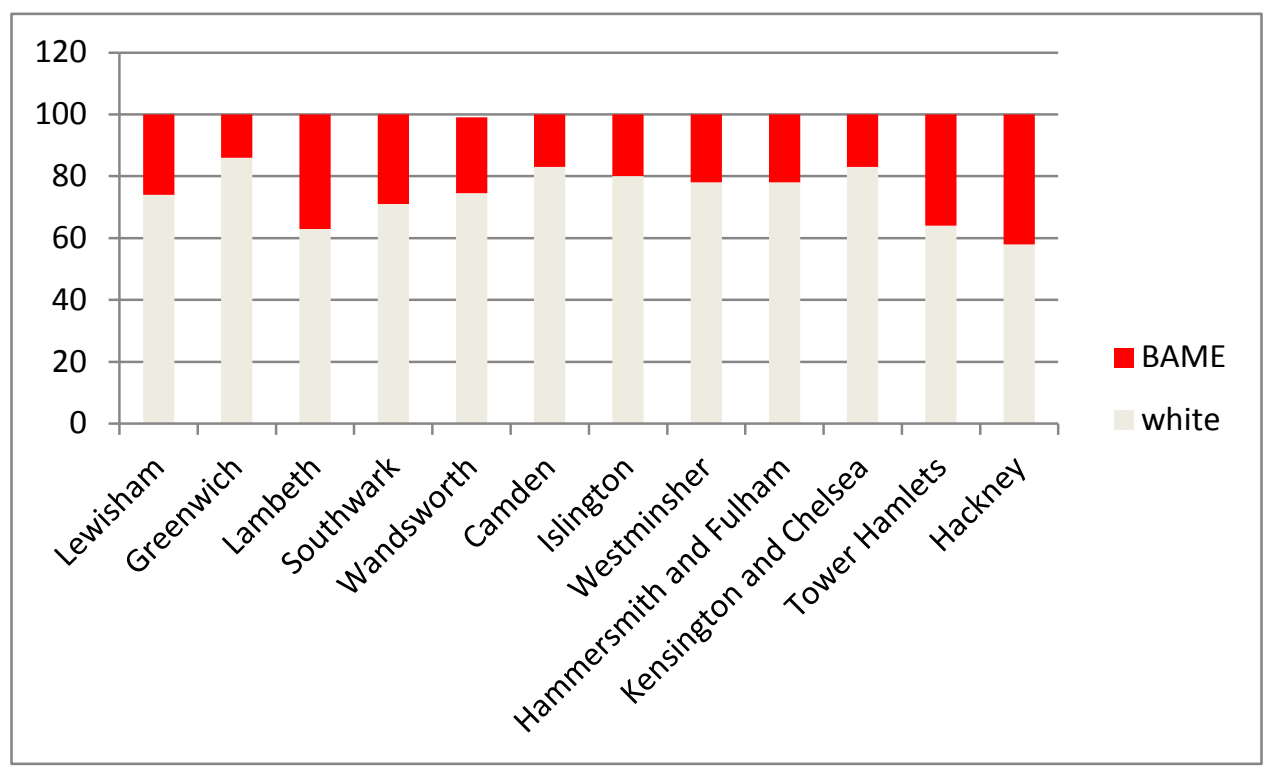

An increase in the ethnic diversity of the adult population is manifested online too, in the limited data made available by the ONS, which indicate the highest rates of internet use (over 90\%) among adults who indicated that their ethnic group was Mixed ethnic, Chinese, Black, or Other. The Pakistani ethnic group remained the group with the lowest rate of use $(82 \%)$ in Q1 2014. (ONS, Internet Access Quarterly update Q1 2014 http://www.ons.gov.uk/ons/rel/rdit2/internet-access-quarterly-update/q1-2014/stb-ia-q1-2014.html\#tab-EthnicGroup).

In short, according to national statistics older age cohorts become more heterogeneous across the UK. On the internet, sex ('gender') remains a manifestation of discrimination among the older adults who are $75+$ and there is a strong correlation with sex, age, and education and internet use. Differences based on sex tend to be confounded with other factors determined by the respondents sex: 'Among this generation, the correlation of sex with education and income is stronger compared to later generations for which educational opportunities were more equal' [7, $\mathrm{p}$. 13) Lastly the limited available data indicate a possibly divergent trend of higher levels of internet use among nonwhite, 'minority ethnic' adult groups.

\section{Older people in digital public service information provision}

The increase in the age, heterogeneity and diversity of adult internet users has been the backdrop to my examination of how older adults are represented visually on local government websites providing information about adult social care support services. Social care support services are provided at local authority level. Access to this kind of support services has been universal, with all UK residents able to use these services. This exploratory study was undertaken in December 2013, as the migration of public service information provision online was underway. The study examined how older adults are represented visually, though the use of pictures and photographs, in the adult social care portal/homepage of in the twelve inner city London Boroughs (Camden, Greenwich, Islington, Lambeth, Lewisham, Southwark, Kensington and Chelsea, Fulham, Tower Hamlets, Hackney, Wandsworth, Westminster) giving a snapshot of cultural attitudes to age in public policy. My research questions follow the work of Loos [1, 2] on older age, information accessibility and the relationship between representations and access to digital services.

A widespread practice in the Borough homepages was to show one or two images of mostly frail looking older people to illustrate their general ID/theme. This was the case of Tower Hamlets ${ }^{2}$ (http://www.towerhamlets.gov.uk/lgnl/ health_and_social _care.aspx), Greenwich

2 This website has now been redesigned and uses icon to represent services and users. 
(http://www.royalgreenwich.gov.uk/info/200050/help_for_adults) Hammersmith and Fulham (http://www.lbhf. gov.uk/ Directory/ Health_and_Social_Care/Services_for_the_elderly/homepage.asp), Lambeth ${ }^{3}$ (http://www. Lambeth.gov.uk/Services/HealthSocialCare/ServicesAdults/).

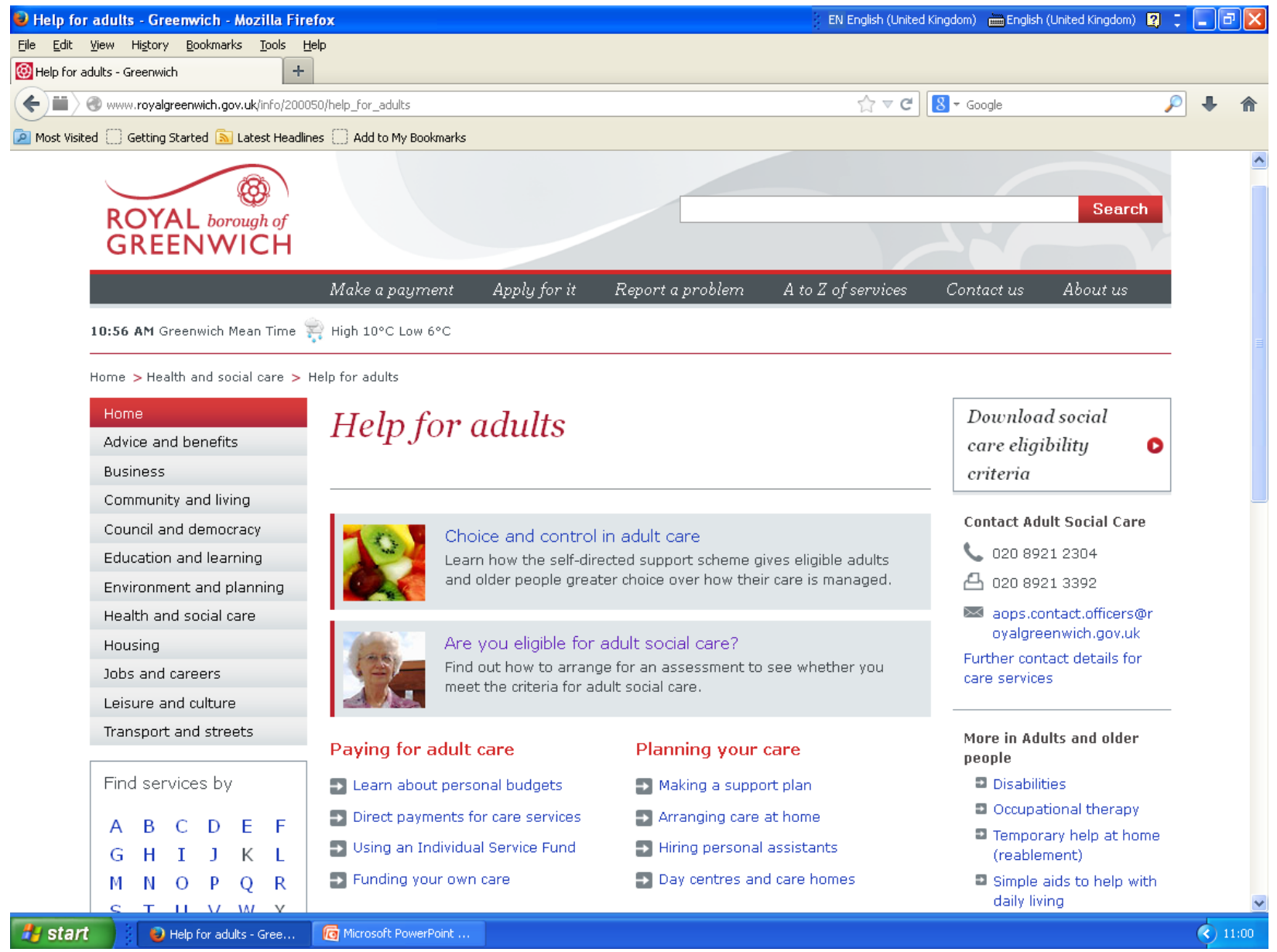

Figure 1. Screenshot of Greenwich Adult Social Care Homepage December 2013

3 The Lambeth pages (http://www.lambeth.gov.uk/Services/HealthSocialCare/ServicesAdults) were redesigned in summer 2014. 


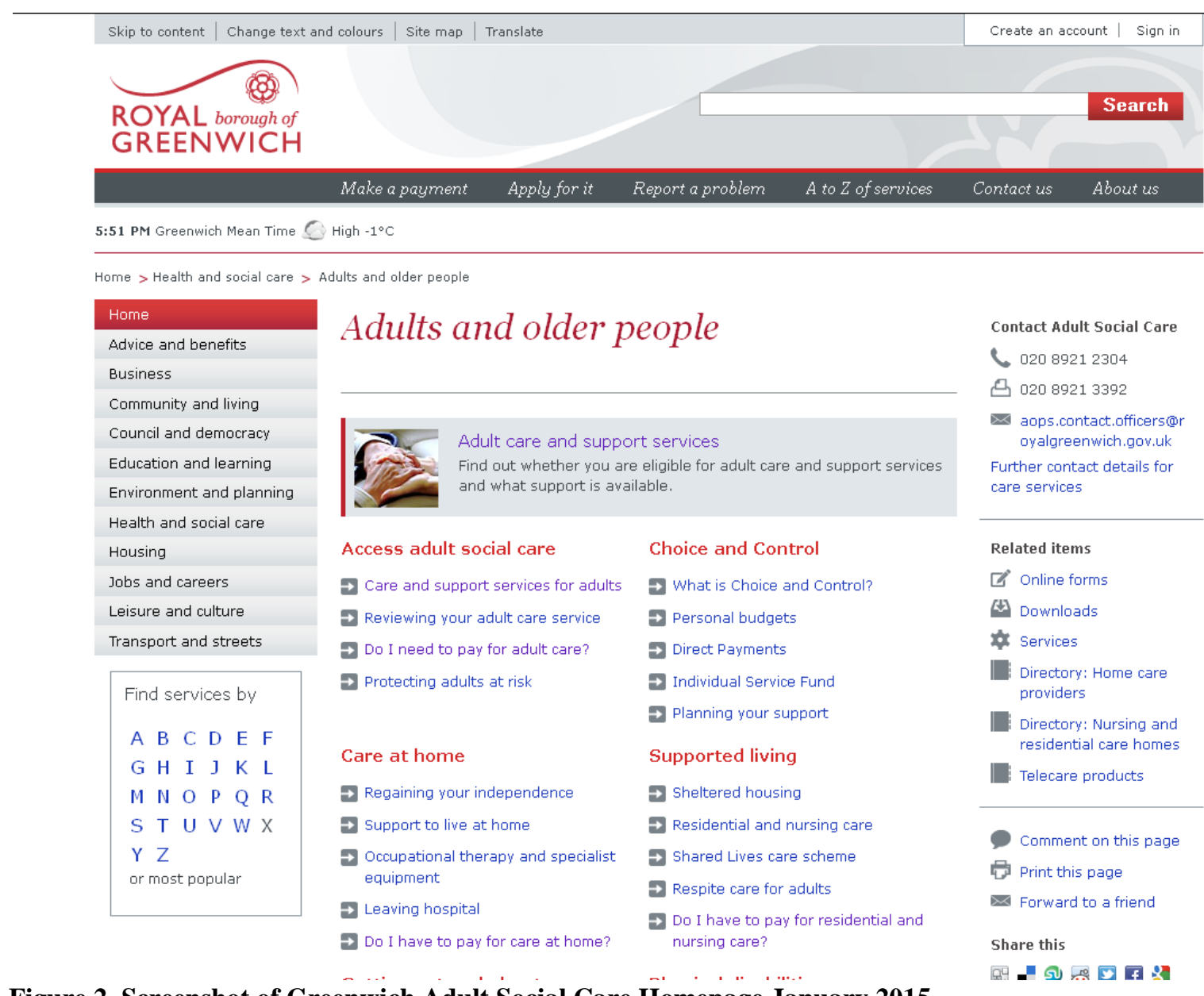

Figure 2. Screenshot of Greenwich Adult Social Care Homepage January 2015

Two trends can be seen in these screenshots: One, there is a restricted visibility of older people in those websites. Images depicting older adults are limited in number. Two, when older people become visible, for example in the updated versions of Council websites, they are depicted as frail, white older women, not making visible potential differences based on sex, ethnic background and vitality. The webpages of Greenwich and Lambeth included some characteristically ageist representations (older lady and fruit assortment on the Greenwich page; a Polaroid picture of young adult woman and man doing craftwork in 1980s' fashion fancy dress on the Lambeth page). The Greenwich social care services website is now redesigned and shows an image of two pairs of hands - the young ones holding the very old ones. In Islington older adults are not visible through images (no depiction of older adults) as all information is text-based (http://www.islington.gov.uk/services/ social-care-health/olderpeople/Pages/default.aspx?extra=4). The websites of Wandsworth (http://www.wandsworth.gov.uk/homepage/146/ adult_care_information_ service) and Southwark (http://www.southwark.gov.uk/info/200387/assessments_ benefits_and_advice) were in the process of adopting a new, more visually oriented online information provision strategy. The Southwark social care home page shows eight older women and men, of which six are white and two are black or mixed race. The Wandsworth Borough page uses graphic icons as navigation buttons and there are no image depicting older people in the main menu of choices.

Two London Boroughs, Camden and Lewisham have implemented a new visual design with simplified, integrated one stop shop services: These Council services make older people visible and recognizable on their homepages. Power relationships of inclusion/exclusion and centring/marginalization can also be observed here. Camden (http://camdencarechoices.camden.gov.uk/) has implemented inclusive and experiential understandings of adult ageing. In the Camden site inclusive social demographics made visible though a lens of dynamic diversity. 
Your guide to adult social care

In Lewisham we want to help people keep well and live independently.

How we can help you today

I'm interested in...

General information

Choices for me

Choices for someone else

You can contact us by phone

Phone 0208314 7777, Monday to Friday from Sam to $5 \mathrm{pm}$

In an emergency, out of these hours

Phone 02083146000

Click here for more information about the Out of Hours Service

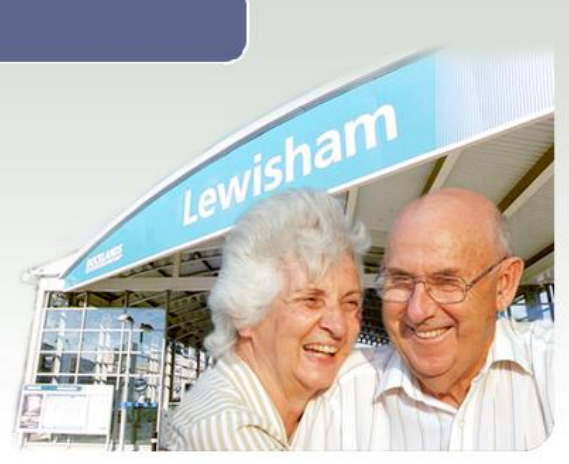



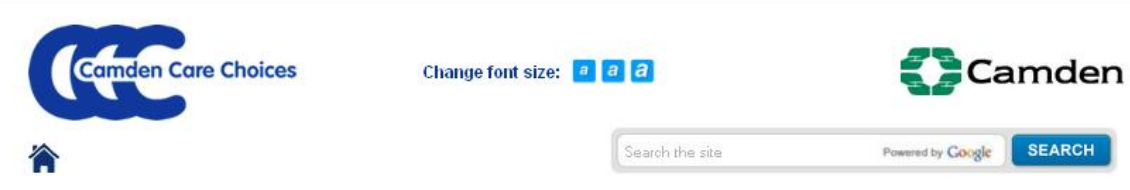

How can we help you today?
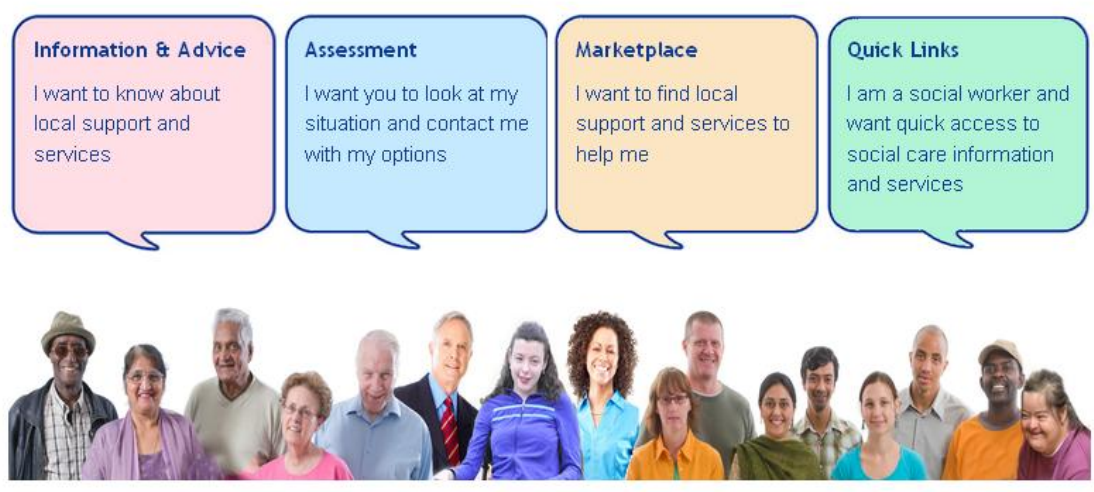

Business | Community and living | Council and democracy | Education | Environment | Housing | Jobs and careers | Leisure
Polioing and publio safety | Social oare and health | Transport and streets

6. Camden Copyright $@ 2011$ | Disclaimer and privacy statement | Contact | Feedback or Report a problem on this site

Q Quidheart 2010

\section{Figure 4. Screenshot of Camden Care Choices}

Camden includes a spectrum of representations with adults of all ages, a range of ethnic groups and equally split sexes (eight women and eight men). By contrast the Lewisham homepage (http://www.lewishammylifemychoice.org.uk/) features a white elderly couple (woman and man). Westminster and Kensington and Chelsea provide both legacy websites and a new, common partnership service called People First http://www.peoplefirstinfo.org.uk/ This external website represents a flagship project which follows current priorities in the reorganization of social health and care services as formalized in the 2014 Care Act, which incorporates Digital by Default design requirements. Lambeth and Southwark are now running a joint social care services information provision and their newly designed website (http://directory.ageuklambeth.org.uk/) is visually inclusive: Images of a multi-ethnic groups of older adults are used, both vitality and frailness women and men.

\section{Discussion and conclusions: Digital public service and the invisible older users}

All twelve Inner London Boroughs provide online information about adult social care, most through dedicated pages. At the time of the research some Boroughs, and more generally local authorities across the country have been redesigning their web services, to meet digital by default targets and therefore the sample provided a good mix of what I'd call 'commonsense' age(ist) values (Greenwich; Lewisham) as well as some newer interpretations of digital inclusion (Camden; Southwark). This study found stereotypical understandings of older age being standing in the wrong end of a 'digital divide' (information 'have-nots', digital 'can-nots') in the visual design of information provision of the local authority websites. The study also found a newly emerging more inclusive visual representation of the age spectrum of adulthood has been in the websites of some Boroughs (Camden). 
Two common visual representations were of old older people as either invisible or non-users of a digital information resource (no pictures as in the case of Islington and Wandsworth) or limited and partial, depicting mostly frail white women. Yet behind this limited and exclusionary representation of older groups of different ages, is a diverse and complex set of differences, both in social demographics and in patterns of internet use as section three showed. Internet use patterns can be seen as functions of inequalities of access to education and cultural and social resources, translating to unequal opportunities to employment for women and men, including 'first generation' immigrants, in the case of people over the age of 75. Translating this complex set of inequalities, and the diversity in the life-world experience of those people to homogenized representations of the old as frail non users of the internet can be seen as unhelpful to access a crude politics of ageism. Recently published studies [e.g. 7, 18] have demonstrated how social position and the social context appears to have a manifold influence on internet use among the older groups of people aged 70+ with the lower levels of internet use. In Friemel's study [7] gender differences in usage, which in the data examined in the present study (UK ONS, 2013-14) are the most pronounced among internet users aged 75+, were found to disappear if controlled for education, income, technical interest, preretirement computer use and marital status. Heatmaps in an eye-tracking study conducted by Loos [10] showed clearly that the navigation patterns of older participants with a high frequency of internet use were quite similar to those of younger ones (see also Hill et al.[19] Dutton et al. [18] demonstrate this for education: virtually all with a higher education degree are using the internet. Homogenous representations of the relationship of older age and new media use may mask, augment and further reinforce disadvantage experienced by older cohorts. Culturally entrenched ageist attitudes, institutionalized practice and research design bias can reinforce the marginalization of older people and reproduce patterns of inequality, including along lines of race and sex.

\section{References}

1. Loos, E.: Senior Citizens. Digital immigrants in their own country? Observatorio (OBS*) Journal 6 (1), 1-23 (2012)

2. Loos, E.: Designing for dynamic diversity: Representing various senior citizens in digital information sources. Observatorio (OBS*) Journal, 7 (1), 21-45 (2013)

3. Hagberg, J.-E.: Being the oldest old in a shifting technology landscape. In: Loos, E, Haddon, L., Mante-Maijer, E. (eds) Generational Use of New Media, pp. 89-106. Ashgate, Farnham (2012)

4. Loos, E., Haddon, H., Mante-Meijer, E. eds: Generational Use of New Media. Ashgate, Farnham (2012)

5. Sourbati, M.: On older people, internet access and electronic service delivery: a study of sheltered homes. In: Loos, E.F., Haddon, L., Mante-Maijer, E.A. (eds.) The Social Dynamics of Information and Communication Technology, pp. 95-104. Ashgate, Aldershot (2008)

6. Vincent, J.A.: Old Age. Routledge: London, Taylor and Francis Group, (2003)

7. Friemel, T.N.: The digital divide has grown old: Determinants of a digital divide among seniors. New Media and Society Online first, June 12 (2014)

8. Prensky, M. Digital Natives, Digital Immigrants. On the horizon, 9 (5), 1-6 (2001)

9. Loos, E.: Generational use of new media and the (ir)relevance of age. In: Colombo, F., Fortunati, L. (eds) Broadband Society and Generational Change, pp. 259-273. Peter Lang, Berlin (2011)

10. Loos, E.:. In Search of Information on Websites: A Question of Age? In: Stephanidis, C. (ed) Universal Access in HCI, Part II, pp. 196-204. Springer, Berlin (2011)

11. Gregor, P., Newell, A.F., Zajicek, M : Designing for dynamic diversity - interfaces for older people. In: Jacko, J.A. (eds) ASSETS 2002 The Fifth International ACM Conference on Assistive Technologies, pp. 151-156 Edinburgh, Scotland, 8-10 July (2002). Available at http://staff.computing.dundee.ac.uk//afn/pdf/2002\%20Dynamic\%20Diversity\%20 _with \%20Mary\%20Z_.pdf [accessed December 2013]

12. Bouma, H.: Document and interface design for older citizens. In: Westendorp, Jansen, C., Punselie, R. (eds), Interface design \& document design, pp.67-80. Rodopi, Amsterdam (2000)

13. Chisnell, D., Redish, J.: Modelling older adults for website design. In: Loos, E., Haddon, L. and Mante-Meijer, E. (eds.) Generational Use of New Media. Ashgate, Farnham (2012)

14. Dannefer, D.: What's in a name? An account of the neglect of variability in the study of ageing. In: Birren, J.E., V.L. Bengtson, V.L. (eds) Emergent theories of ageing, pp. 356-384. Springer, New York (1988)

15. Office of National Statistics (ONS) Internet Access Quarterly update Q1 2014 http://www.ons.gov.uk/ons/rel/rdit2/internetaccess-quarterly-update/q1-2014/stb-ia-q1-2014.html\#tab-Ethnic-Group (2014)

16. Sparks, C.: What is the "digital divide" and why is it important? In: Javnost - The Public 20 (2), 27-46 (2013) http://javnost-thepublic.org/issue/2013/2/ (2013)

17. Office of National Statistics (ONS) Internet Access Quarterly update, Q 22013 http://www.ons.gov.uk/ons/rel/rdit2/internetaccess-quarterly-update/q2-2013 /stb-ia-q2-2013.html\#tab-Age-and-sex. 
18. Dutton, W.H., Grant, B. with Groselj, D.: Oxford Internet Survey 2013 Report: Cultures of the internet. Oxford Internet Survey, OxIS. (2013) http://oxis.oii.ox.ac.uk/reports (2013)

19. Hill, R., Dickinson, A., Arnott, J., Gregor, P., McIver, L. (2011). Older users' eye movements: Experience counts, CHI 2011, May 7-12 Vancouver, BC, Canada. (2011)

Cabinet Office (2013) 'Government's approach to assisted digital' Policy Paper, 4 December 2013. http://publications.cabinetoffice.gov.uk/digital/assisted/ 